OPEN ACCESS

Edited by: Irene Murgia,

Università degli Studi di Milano, Italy

Reviewed by:

Alex Levine,

Hadassah Medical School, Israel

Jutta Ludwig-Müller,

Technische Universität Dresden,

Germany

*Correspondence:

Günther F. E. Scherer

scherer@zier.uni-hannover.de

Specialty section: This article was submitted to

Plant Physiology,

a section of the journal

Frontiers in Plant Science

Received: 25 February 2016 Accepted: 22 June 2016

Published: 11 July 2016

Citation:

Labusch C, Effendi Y, Fulda M and Scherer GFE (2016) Transcription of TIR1-Controlled Genes Can be Regulated within 10 Min by an Auxin-Induced Process. Can TIR1 be the Receptor? Front. Plant Sci. 7:995. doi: 10.3389/fpls.2016.00995

\section{Transcription of TIR1-Controlled Genes Can be Regulated within 10 Min by an Auxin-Induced Process. Can TIR1 be the Receptor?}

\author{
Corinna Labusch ${ }^{1}$, Yunus Effendi1,2, Martin Fulda ${ }^{3}$ and Günther F. E. Scherer ${ }^{\text {* }}$
}

${ }^{1}$ Abteilung Molekulare Ertragsphysiologie, Institut für Gartenbauliche Produktionssysteme, Leibniz Universität Hannover, Hannover, Germany, ${ }^{2}$ Department of Biology, University of Al Azhar Indonesia, Jakarta, Indonesia, ${ }^{3}$ Abteilung Biochemie der Pflanzen, Albrecht-von-Haller-Institut der Pflanzenwissenschaften, Universität Göttingen, Göttingen, Germany

ABP1 and TIR1/AFBs are known as auxin receptors. ABP1 is linked to auxin responses several of which are faster than $10 \mathrm{~min}$. TIR1 regulates auxin-induced transcription of early auxin genes also within minutes. We use transcription of such TIR1-dependent genes as indicator of TIR1 activity to show the rapid regulation of TIR1 by exogenous auxin. To this end, we used quantification of transcription of a set of fifteen early auxininduced reporter genes at $t=10$ and $t=30 \mathrm{~min}$ to measure this as a TIR1-dependent auxin response. We conducted this study in 22 mutants of auxin transporters (pin5, abcb1, abcb19, and aux1/lax3), protein kinases and phosphatases (ibr5, npr1, cpk3, CPK3-OX, d6pk1, d6pkl1-1, d6pk/3-2, d6pk/1-1/d6pkl2-2, and d6pkl1-1/d6pk/3-2), of fatty acid metabolism (fad2-1, fad6-1, ssi2, lacs4, lacs9, and lacs4/lacs9) and receptors (tir1, tir1/afb2, and tir1/afb3) and compared them to the wild type. After 10 min auxin application, in 18 out of 22 mutants mis-regulated expression of at least one reporter was found, and in 15 mutants transcription of two-to-three out of five selected auxin reporter genes was mis-regulated. After 30 min of auxin application to mutant plants, mis-regulation of reporter genes ranged from one to 13 out of 15 tested reporter genes. Those genes chosen as mutants were themselves not regulated in their expression by auxin for at least $1 \mathrm{~h}$, excluding an influence of TIR1/AFBs on their transcription. The expression of TIR1/AFB genes was also not modulated by auxin for up to $3 \mathrm{~h}$. Together, this excludes a feedback or feedforward of these mutant genes/proteins on TIR1/AFBs output of transcription in this auxin-induced response. However, an auxininduced response needed an as yet unknown auxin receptor. We suggest that the auxin receptor necessary for the fast auxin-induced transcription modulation could be, instead, ABP1. The alternative hypothesis would be that auxin-induced expression of a protein, initiated by TIR1/AFBs receptors, could initiate these responses and that this unknown protein regulated TIR1/AFB activities within 10 min.

Keywords: AUXIN-BINDING PROTEIN 1, early auxin-induced genes, auxin transport mutants, auxin receptor mutants, fatty acid-metabolism mutants, protein kinase mutants, protein phosphatase mutants, TRANSPORT INHIBITOR RESPONSE 1

Abbreviations: ABP1, AUXIN BINDING PROTEIN1; AFBs, AUXIN SIGNALING F-BOX proteins; Aux/IAA protein, Auxin/indoleacetic acid protein; PIN protein, PIN-FORMED protein; pPLA, patatin-related Phospholipase A; SAUR, small auxin-up RNA; TIR1, TRANSPORT INHIBITOR RESPONSE 1. 


\section{INTRODUCTION}

Auxin plays an essential role in plant growth and development. Auxin is perceived by three receptors, ABP1 on the outer surface of the plasma membrane and the TIR1/AFBs in the nucleus (Badescu and Napier, 2006). The TIR1/AFB receptors are encoded by a small gene family (Parry et al., 2009); ABP1 is encoded by a single gene (Chen et al., 2001). A third auxin receptor, SKP2A, has a specialized function in activating the cell cycle (Jurado et al., 2010) and is not relevant for this study on auxin-induced transcription.

The mechanism of auxin binding to TIR1 and Aux/IAA proteins (auxin/indole-acetic acid proteins) in a sandwich complex has been investigated in great detail (Tan et al., 2007; Calderon-Villalobos et al., 2012; Salehin et al., 2015). Ubiquitination of the bound Aux/IAA proteins by $\mathrm{SCF}^{T I R 1}$ and their subsequent proteolysis in the proteasome prevents them from binding to ARF transcription factors, thereby modulating the expression of early auxin-induced genes (Mockaitis and Estelle, 2008). TIR1/AFB activities, measured as degradation of IAA-luciferase proteins, was shown to increase within less than 2 min upon auxin administration (Zenser et al., 2003). A second method to measure TIR1 activity is the quantification of transcription of the early auxin-induced genes, which can thus be used as a specific test for TIR1/AFB activities (Salehin et al., 2015). Auxin-induced transcriptional changes can be measured within a few minutes (Abel and Theologis, 1996). Hence, transcription of auxin-inducible genes can be used like many other auxin biotests but with the great advantage that molecular details are already well-known and the chain of events from receptor to transcription control is short.

ABP1 is a small glycoprotein localized on the extracytosolic side of the plasma membrane and in the ER (Napier et al., 2002) and is important for many rapid cellular changes (Badescu and Napier, 2006). Recently it was shown that ABP1 plays no role in embryo development as previously postulated (Chen et al., 2001) so that its role in auxin signaling has been questioned (Dai et al., 2015; Gao et al., 2015). However, ABP1 binds to TMK1, a transmembrane receptor kinase, and this activates small G-protein signaling in the cytosol (Dai et al., 2013; Xu et al., 2014) and, conceivably, this mechanism is suitable to also activate other processes in the cytosol. Therefore, the transmembrane signaling function of ABP1 could potentially reach many targets within minutes.

It is more difficult to relate the TIR1/AFB receptors to rapid auxin responses within 5-10 $\mathrm{min}$ because transcription/translation is the mechanism of action of TIR1/AFBs, and regulation of proteins other than those translated from early auxin genes has not been proven to be so rapid. But the genes of numerous mutants in auxin signaling or physiology were described which are not part of the machinery regulating promoter activity of primary auxin genes.

The mutants used in this investigation and previously (Effendi et al., 2011, 2013, 2015; Labusch et al., 2013) are potentially related to rapid auxin responses. The transcription of all these mutant genes is not regulated by auxin during the first hour as was documented (Nemhauser et al., 2006'). Therefore, it is difficult to assume that there is transcriptional feedback or feedforward to TIR1/AFB activity through these mutated proteins/genes investigated here. But, we could find in the mutants used here and previously, changes in TIR1/AFBcontrolled and auxin-induced transcription of early auxininduced genes at $t=10 \mathrm{~min}$ and $t=30 \mathrm{~min}$, thus indicating an auxin receptor-driven process influencing TIR1/AFB activities. This auxin receptor-driven process potentially acts in parallel or in addition to TIR1/AFBs receptors.

Known rapid auxin-induced responses measured within 5$10 \mathrm{~min}$ or even less influenced selection of the mutants in our investigations. Examples of rapid responses are the activation of the pPLA (Paul et al., 1998) and the $\mathrm{H}^{+}$ATPase (Takahashi et al., 2012; Fuglsang et al., 2014). Both enzymes are phosphorylated and, additionally, auxin-induced phosphorylation was reported in other systems (Mockaitis and Howell, 2000) so that, we included auxinic mutants affecting protein phosphatases (ibr5, npr1) (Garbers et al., 1996; MonroeAugustus et al., 2003) and kinases (cpk3, CPK3-OX, d6pk1, d6pkl1-1, d6pkl3-2, d6pkl1-1/d6pkl2-2, and d6pkl1-1/d6pkl3-2) (Zegzouti et al., 2006; Strader et al., 2008; Zourelidou et al., 2009, 2014; Mehlmer et al., 2010; Rietz et al., 2010). Furthermore, inhibition of clathrin-dependent endocytosis of PIN proteins is a rapid auxin response (Robert et al., 2010; Xu et al., 2010), as is auxin transport itself (Petrasek et al., 2006). This prompted us to include mutants in auxin transport proteins, PIN5 (Mravec et al., 2009) and previously PIN2 (Effendi and Scherer, 2011) as well as in ABCB1, ABCB19, and AUX1 (Geisler et al., 2003; Péret et al., 2012). Lipids are substrates for PPLA and PIN proteins interact with lipids (Roudier et al., 2010; Markham et al., 2011) both of which could influence the responses to auxin in mutants in membrane lipid metabolism. Mutants in TIR1 and $A F B$ genes were chosen because, so far, we had investigated only mutants of the $A B P 1$ gene.

As a method, we had previously used a set of transcripts (IAA2, IAA3, IAA11, IAA13, IAA14, IAA19, IAA20, SAUR9, SAUR15, SAUR23, GH3-5, PIN1, PIN2, PIN3, and PIN5) to report transcription induced by auxin and, hence, TIR1/AFB activities (Effendi et al., 2011, 2013, 2015; Labusch et al., 2013). Some are well-accepted rapid auxin response transcripts, like SAURs, and most belong to the known gene families of early auxin-induced genes (Vieten et al., 2005; Paponov et al., 2008).

As with the previously investigated mutants, our results support the observations that TIR1/AFB activities can be regulated within $10 \mathrm{~min}$ by an auxin-initiated and receptordriven process. Despite some recent doubts about the signaling function of ABP1 (Gao et al., 2015), new findings on ABP1 indicate that ABP1 (Dai et al., 2013; Xu et al., 2014) could be an auxin receptor acting rapidly by a post-translational mechanism that can operate on a time scale from 0 to $10 \mathrm{~min}$. This poses the question: can TIR1/AFBs be the receptors to initiate this response or is it more likely that a second receptor can fulfill such a function?

${ }^{1}$ http://jsp.weigelworld.org/expviz/expviz.jsp 


\section{MATERIALS AND METHODS}

\section{Plant Material and Growth Conditions}

Seedlings seeds were surface- sterilized, stratified for 2-4 days, and grown under long day conditions $\left(22^{\circ} \mathrm{C} ; 16 \mathrm{~h}\right.$ white light, $8 \mathrm{~h}$ dark, 30-40 $\mu \mathrm{E}$ ) in $500 \mu \mathrm{L} \mathrm{MS} / 2$ liquid medium for 7 days in small hydrophilic Petri dishes $(5 \mathrm{~cm})$ until they had 2-4 primary leaves. Prior to treatment with auxin the medium was replaced by $450 \mu \mathrm{L}$ fresh medium. After $4 \mathrm{~h}$ equilibration to the fresh medium, seedlings were treated either with $50 \mu \mathrm{L}$ $100 \mu \mathrm{M}$ IAA $(10 \mu \mathrm{M}$ final concentration) prepared from a $20 \mathrm{mM}$ stock solution in DMSO or only with $\mathrm{MS} / 2$ liquid medium containing the same amount of DMSO for 10 or $30 \mathrm{~min}$. Plant material was quickly blotted on filter paper and frozen in liquid nitrogen.

\section{Mutants Used in this Study}

For quantification of TIR1-dependent transcription, we selected a set of reporter genes and included in addition several PIN genes of potential importance (IAA2, IAA3, IAA11, IAA13, IAA14, IAA19, IAA20, SAUR9, SAUR15, SAUR23, GH3-5, PIN1, PIN2, $P I N 3$, and PIN5). The primary auxin responsive genes include three gene families called $A u x / I A A, G H 3$, and SAUR (Abel and Theologis, 1996; Paponov et al., 2008). Expression of many of these genes was up-regulated within minutes of exposure to auxin and was independent of de novo protein synthesis (Abel and Theologis, 1996). Aux/IAA proteins are short lived and they play a crucial role in auxin-mediated signaling (Mockaitis and Estelle, 2008). The GH3 gene family in Arabidopsis encodes IAA-amido synthetases that have the function to maintain IAA homeostasis in converting auxin to inactive amino acid conjugates (Staswick et al., 2005). Expression of SAUR mRNAs was induced by auxin within 2 to $5 \mathrm{~min}$ (Abel and Theologis, 1996). The protein function is still mostly unknown but they are thought to be involved in auxin signal transduction, auxin transport and elongation (Chae et al., 2012; Spartz et al., 2012, 2014). We also chose several additional genes of interest (PIN1, PIN2, PIN3, and PIN5), which we had used before to characterize abp1 and ppla mutants (Effendi et al., 2011; Labusch et al., 2013). Details of the sources of the mutants are found in Supplementary Table S1.

\section{Nucleic Acid Analysis}

For quantitative RT-PCR, we employed methods as previously described (Labusch et al., 2013). Total RNA from auxin treated seedlings was prepared using TRIzol reagent according to the manufacturer's instructions (Invitrogen), treated with DNase I (Invitrogen) and converted to cDNA with RevertAid $\mathrm{H}$ Minus First Strand cDNA Synthesis kit (Fermentas). Primer efficiency was checked by using different cDNA concentrations and only primer with mathematical efficiency between 95 and $105 \%$ were used. Primers are listed in supplemental material (Supplementary Table S1). For quantitative PCR reactions SYBRGreen Master Mix was used in a StepOnePlus system (Applied Biosystem). About $30 \mathrm{ng}$ cDNA, $200 \mathrm{nM}$ primers, $0.5 \mu \mathrm{M}$ ROX (Invitrogen), 0.1x SYBR Green (Invitrogen), and $0.03 \mathrm{U}$ Hot Start Polymerase (DNA cloning service) were utilized in one PCR reaction. The specificity of PCR amplification was examined by monitoring the presence of a single peak in the melting curves for quantitative PCR. In each experiment four to six biological repeats, and for each biological treatment three technical repeats were performed for the subsequent qPCR reaction. Relative expression calculation and statistical analysis were done with REST 2009 software (Pfaffl et al., 2002). The values for $t=0 \mathrm{~min}$ in untreated wt and mutants were separately calculated relative to the ubiquitin10 gene reference gene. The expression level of the untreated controls in the wt and the mutants was set as one fold and auxin modulation accordingly at $t=10$ and $t=30$ min values. Data on primers and sources of mutants are in Supplementary Tables S1 and S2.

\section{RESULTS}

\section{Auxin Transport Mutants Modulate Expression of Reporter Genes}

Mutants of three different types of auxin transport proteins, pin5, abcb1, abcb19 (efflux transporter), and the double mutant aux1/lax3 (influx transporter) (Geisler et al., 2003, 2005; Mravec et al., 2009; Titapiwatanakun et al., 2009; Péret et al., 2012), were investigated whether or not they modulate early auxin-induced reporter gene expression at $30 \mathrm{~min}$ (Figure 1).

We wanted to quantify transcription as a response to auxin so that, we compared transcriptional abundance at $t=0 \mathrm{~min}$ in the wt to transcription at $30 \mathrm{~min}$ (or $10 \mathrm{~min}$, see below) after auxin addition. In the wt the fold transcriptional abundance of a reporter gene at $t=0$ in comparison to the internal standard gene was determined and set as one fold. The fold expression change at $t=30 \mathrm{~min}$ in the wt was calculated in comparison to the $t=0 \mathrm{~min}$ value (being set as 1 ). This fold-induction by auxin corresponds to one bar for a reporter gene in the diagram for the wt (Figure 1). In the mutants the measurements and the calculations were done in the same way. Hence, for all reporter genes a series of fold-values was generated at $30 \mathrm{~min}$ for the wt and for all mutants. Comparing these patterns in the wt and mutants reflects the auxin responsiveness of transcription of the reporter genes in the lines at $t=30 \mathrm{~min}$ (or at $t=10 \mathrm{~min}$, see below). Differences between the wt and the mutants of auxin in responsiveness can be detected even if the base value at $t=0 \mathrm{~min}$ is not identical in the wt and the mutants. The relative transcription of the reporter genes after 7 days of development in the mutants without auxin treatment indeed is not identical to the one at $t=30 \mathrm{~min}$ or $t=10 \mathrm{~min}$ (Supplementary Figures S1-S6). Of the PIN genes tested only transcription of PIN3 turned out to be auxin-sensitive and transcription of PIN1, PIN2, and PIN5 were not. On the other end of the auxin-sensitivity scale other genes were consistently found (IAA19, SAU9, SAUR15, SAUR25, and $G H 3.5)$, especially, when the total of results were compared (see below). Hence, the overall pattern of all measurements for each mutant of all reporter genes can be taken as a pattern of the fast responsiveness to auxin of that mutant. The slow response is the pattern of transcription after 7 days development $(t=0 \mathrm{~min})$. 

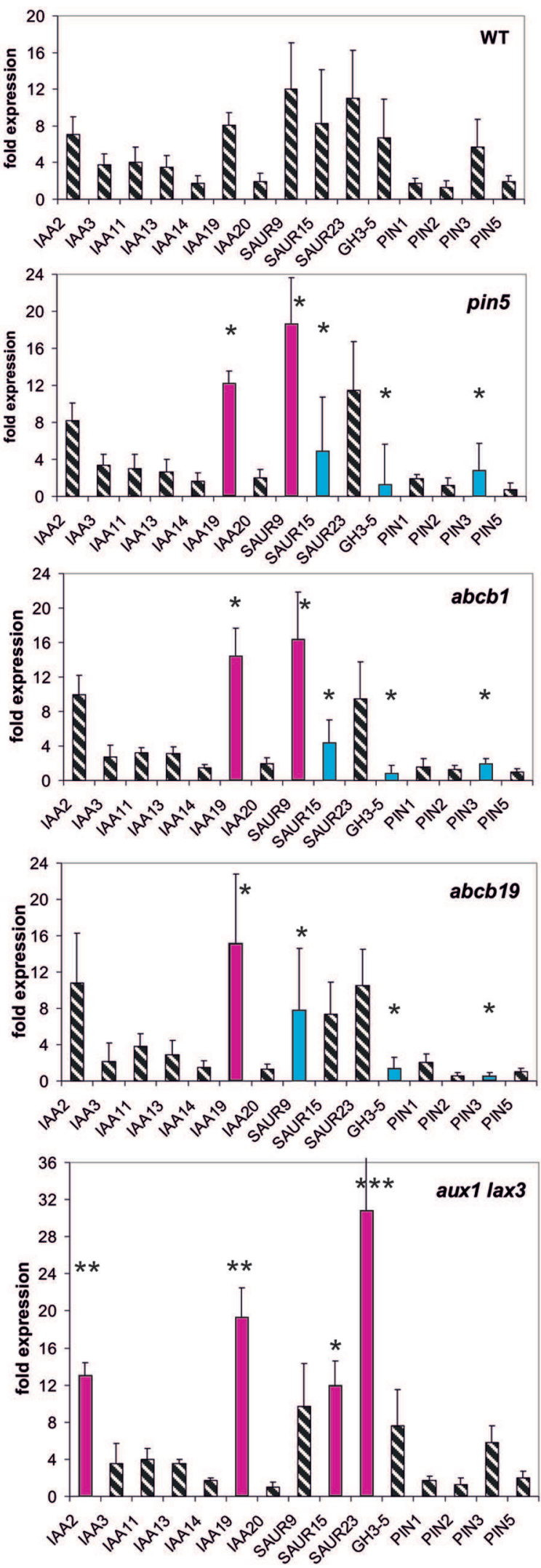

FIGURE 1 | Continued
FIGURE 1 | Continued

Auxin-induced transcription of reporter genes in seedlings of mutants pin5, abcb1, abcb19, aux1/lax3, and wild type (wt) seedlings. Seedlings were grown in the light for 7 days and auxin treatment was for $30 \mathrm{~min}$. For each, the wt and the mutants, one panel is shown for the reporter genes. Red bars indicate significant increased and blue bars significantly decreased transcription of reporter genes in comparison between the wt and mutant. Striped bars indicate no significant difference between the wt and the mutant. Transcription in the untreated wt and mutants at $t=0$ min were set at 1 , and values after $10 \mu \mathrm{M}$ treatment by IAA at $t=30$ min were calculated relative to these values and represent as a bar either in the wt or in a mutant diagram $\left[{ }^{*} p<0.05,{ }^{* *} p<0.01,{ }^{* * *} p<0.001 ; t\right.$-test $]$.

In aux1/lax3 plants four reporter genes were transcriptionally up-regulated compared to the wt (IAA2, IAA19, SAUR15, and SAUR23). The overall pattern of expression in aux1/lax3 mutants was different from and differences were greater than those in the other transport mutants. In pin 5 and $a b c b 1$ the transcription of IAA19 and SAUR9 was increased compared to the wt, whereas SAUR15, GH3.5, and PIN3 were down-regulated in response to auxin compared to the wt. Both patterns were similar. Auxininduced transcription in $a b c b 19$ was overall similar to pin5 and $a b c b 1$ but SAUR9 and SAUR15 were transcribed at the wt level.

We noticed that in the mutants used here not only the rapid auxin-induced expression was different from the wt but also the expression pattern of these reporter genes prior to auxin challenge, i.e., at $t=0 \mathrm{~min}$ (Supplementary Figure S1). Expression at $t=0$ is equivalent to long-term developmental patterns in transcription of the reporter genes. When, we compared the wt versus mutants without auxin treatment $(t=0 \mathrm{~min}$ ) (Supplementary Figure S1), we found that the misexpression of reporter genes at $t=0$ min among pin5, abcb1, and $a b c b 19$ was remarkably similar, encompassing the same five reporter genes (IAA2, IAA3, IAA14, IAA19, and PIN3) and in aux1/lax3, again, IAA2, IAA3, IAA14, SAUR9, and PIN3 (but not IAA19). Several more mis-regulated reporter genes, being different in different mutants, were also found in each of the transporter mutants.

\section{Protein Phosphatases and Kinases as Potential Auxin Signaling Intermediates Modulate Expression of Reporter Genes}

A number of protein kinases and phosphatases (cpk3, d6pk's, $i b r 5$, and $r c n 1$ ) are known to be auxin signaling mutants. CPK3 phosphorylated and activated pPLA enzymatic activity and $C P K 3-O X$ is an over-expressing line for this gene (Mehlmer et al., 2010; Rietz et al., 2010). The weak auxin signaling mutant ibr5 (Monroe-Augustus et al., 2003; Strader et al., 2008) and the gravitropic mutant $r c n 1$ are protein phosphatase mutants (Garbers et al., 1996). Further kinases having functions in the regulation of PIN polarity and activity are the D6P kinases (Zourelidou et al., 2009, 2014). Therefore, the respective D6PK mutants were investigated.

Whereas in the cpk3 mutant only one reporter gene, PIN3, was mis-expressed in CPK3-OX, in $i b r 5$ and $r c n 1$ four to five genes were mis-expressed after $30 \mathrm{~min}$ (Figure 2). In all, the 

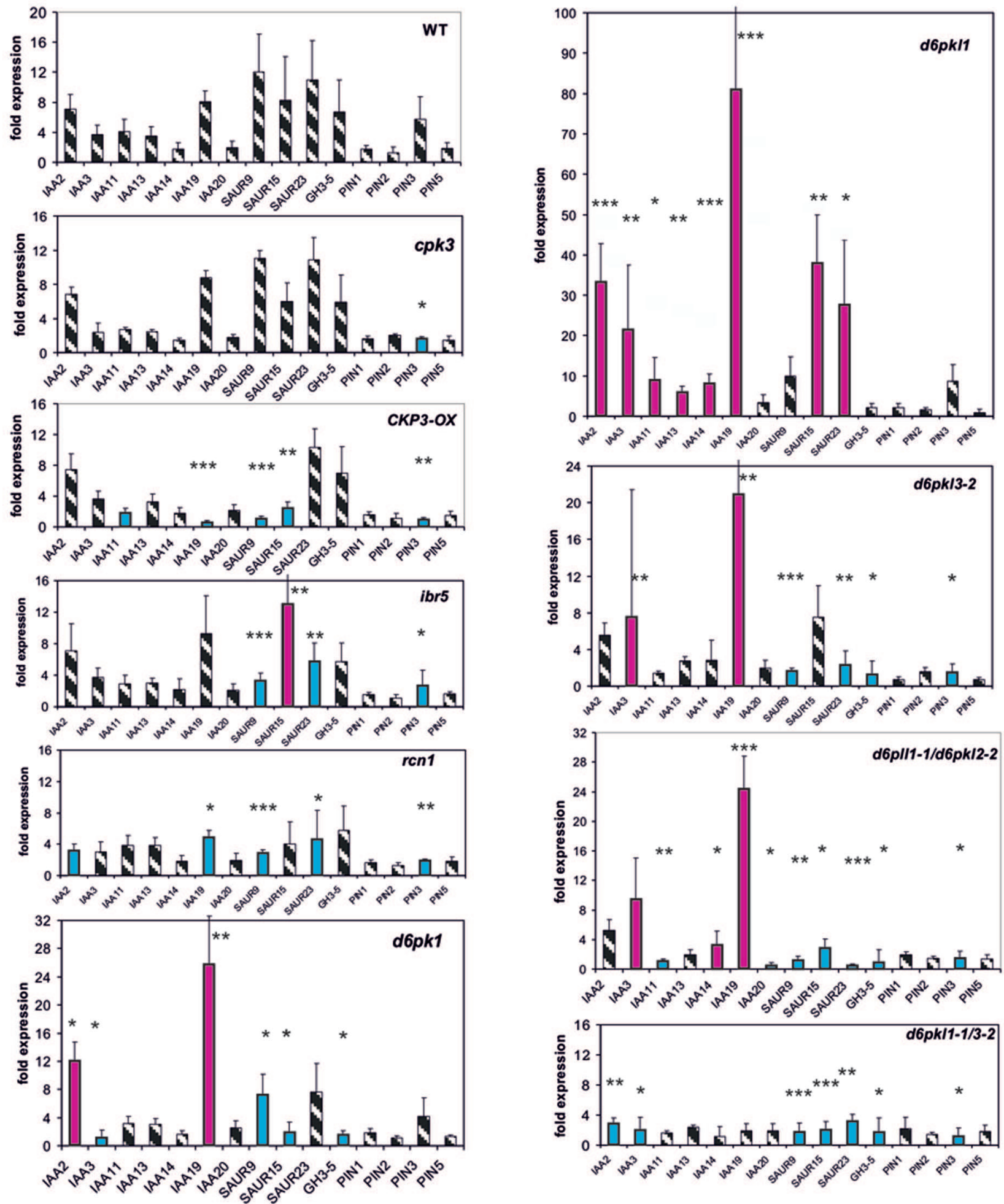

FIGURE 2 | Auxin-induced transcription of reporter genes in seedlings of mutants cpk3, the over-expressor CPK3-OX, ibr5, rcn1, d6pk-1, d6pkl-1-1,

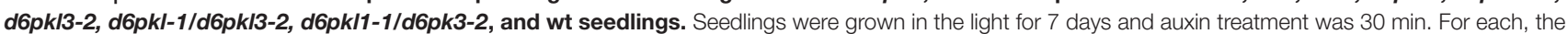
wt and the mutants, one panel of the reporter genes is shown. Red bars indicate significant increased of transcription and blue bars significantly decreased transcription of reporter genes in a comparison between the wt and mutant. Striped bars indicate no significant difference between the wt and the mutant. Transcription in the untreated wt and mutants at $t=0$ min were set as 1 and values after $10 \mu \mathrm{M}$ treatment by IAA at $t=30$ min were calculated relative to these values and represent as one bar either in the wt diagram or in a mutant diagram $\left[{ }^{*} p<0.05,{ }^{* *} p<0.01,{ }^{* * *} p<0.001 ; t\right.$-test]. 
differences as compared to the wt were small. The only gene which was mis-regulated in all four mutants was SAUR23. At $t=0$, in $c p k 3, C P K 3-O X$, ibr5, and $r c n 1$ only $1-4$ reporter genes were mis-regulated (Supplementary Figure S2).

In the second group of protein kinase mutants ( $d 6 p k-1, d 6 p k l$ 1 , d6pkl3-2 and the double mutants d6pkl1-1/2-2 and d6pkl1$1 / d 6 p k l 3-2)$ mis-expression of 6-10 reporter genes after $30 \mathrm{~min}$ was found to be substantially different from the wt (Figure 3). In contrast to most other mutants investigated, in the mutant d6pkl-1 mis-expression of IAA genes was not delayed but always higher than in the wt after $30 \mathrm{~min}$. At $t=0 \mathrm{~min}$ in the mutants of D6PK or D6PKL kinases the number of mis-expressed genes was 9-13 reporter genes (Supplementary Figure S2), which probably is related to the fact that the second group of protein kinases, the D6PKs, has different functions in auxin-signaling (Zourelidou et al., 2009, 2014).

\section{Lipid Metabolism Enzymes Interfere with Transcription of Reporter Genes}

Another group of proteins linked to pPLA activation by auxin could be enzymes of lipid metabolism whose mutations lead to an altered membrane lipid composition compared to the wild type (wt; fad2-1, fad6-1, ssi2, lacs4, and lacs9) (Wallis and Browse, 2002; Kachroo et al., 2003; Zhang et al., 2009, 2012). Likewise, such mutations of lipid metabolism could highlight the importance of membrane lipid composition for the activity of transport proteins like PINs as a more indirect influence on auxin responsiveness (Roudier et al., 2010; Markham et al., 2011).

The single mutants lacs 4 and lacs 9 proved to be only weak mutants in which only one reporter gene was mis-regulated (Figure 3). In the mutants fad2-1, ssi2 and in the lacs4/lacs9 double mutant, we observed similarities in the patterns of mis-regulation in IAA19, SAUR9, GH3.5, and PIN3 at $30 \mathrm{~min}$ (Figure 3). In fad6-1 up-regulation of transcription was observed in the three SAUR genes.

Surprisingly, at $t=0 \mathrm{~min}$ in the single lacs mutants five genes and in the double mutant expression of 10 reporter genes was differentially regulated (Supplementary Figure S3), and four among them were identical in each mutant (IAA14, IAA20, SAUR15, and SAUR23). This may indicate again a similar functional impact of these long chain acyltransferases on certain auxin functions like auxin transport.

\section{Receptor Mutants of the TIR1/AFB Family Modulate Reporter Genes Weakly}

Finally, we investigated the reporter gene expression in the auxin receptor mutants $t i r 1$, tir1/afb2, and tir1/afb3 (Figure 4). The TIR1/AFB gene family encompasses six genes and their expression is not regulated by auxin (Parry et al., 2009). After 30 min auxin treatment only two genes were weakly misexpressed in tir1 (Figure 4). At $t=30 \mathrm{~min}$ mis-expression was almost identical in both double mutants tirl/afb2 and tirl/afb3 affecting 6-7 reporter genes (IAA11, IAA19, SAUR9, SAUR13, SAUR15, and PIN3). The magnitude of mis-expression was considerably higher in the double mutants as compared to the single mutant tirl, and transcription of two reporter genes
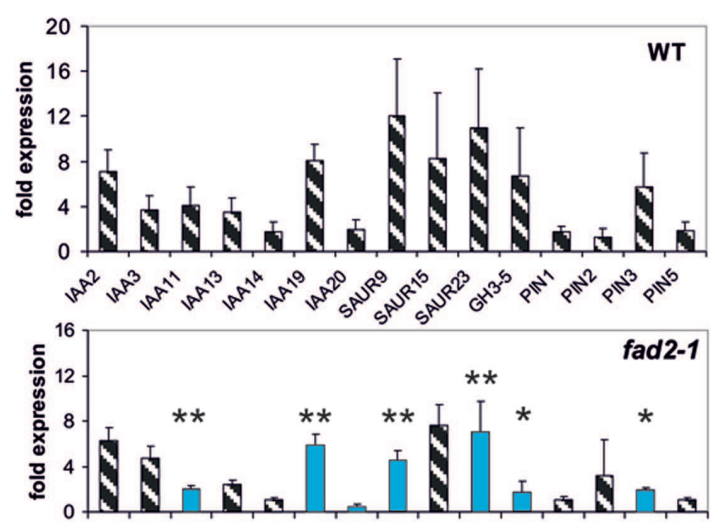

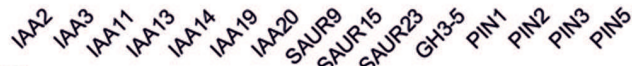
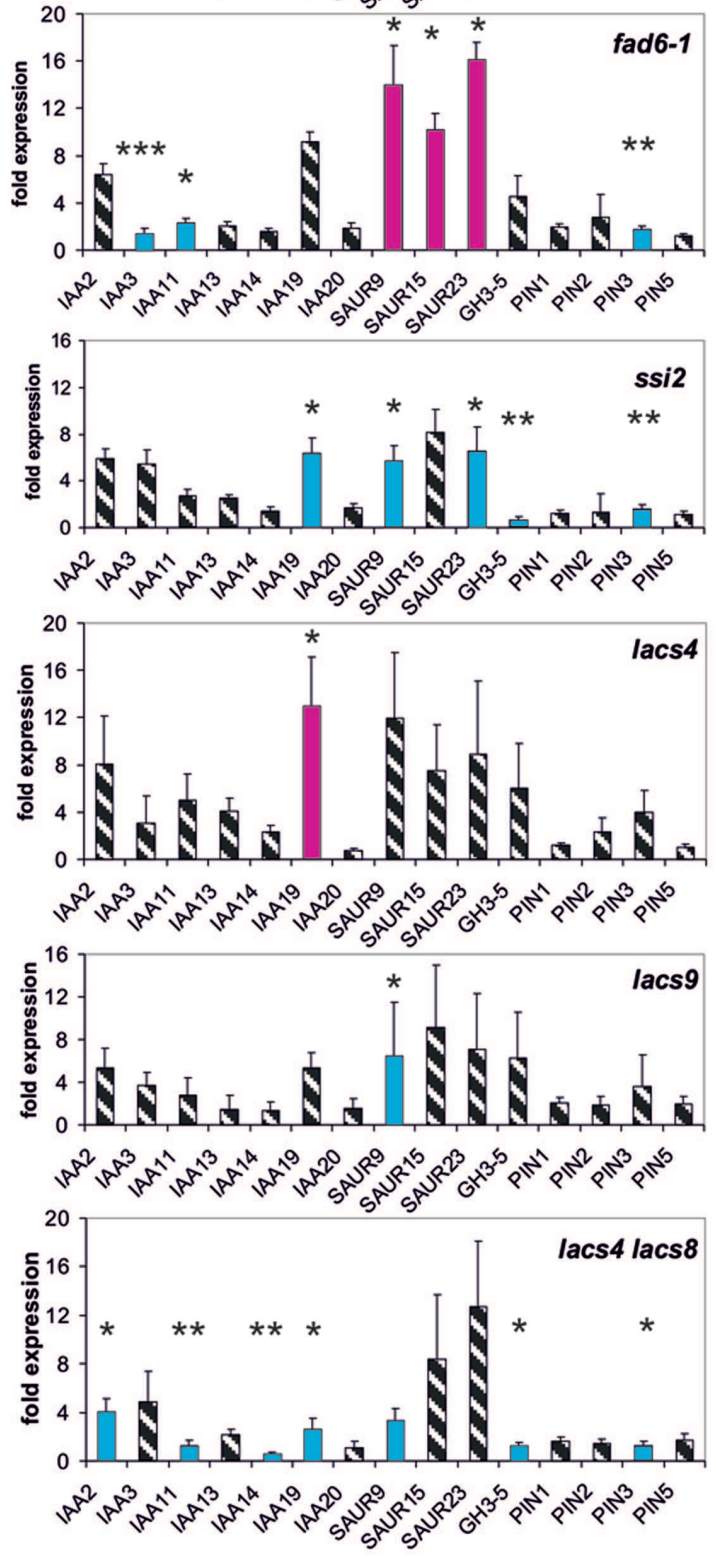

FIGURE 3 | Continued 


\section{FIGURE 3 | Continued \\ Auxin-induced transcription of reporter genes in seedlings of the mutants fad2-1, fad6-1, ssi2, lacs4, lacs9, lac4/lacs9, and wt seedlings. \\ Seedlings were grown in the light for 7 days and auxin treatment was $30 \mathrm{~min}$. For each of the wt and the mutants, one panel for the reporter genes is shown. Red bars indicate significant increased transcription and blue bars significantly decreased transcription of reporter genes in a comparison between the wt and mutant. Striped bars indicate no significant difference between the wt and the mutant. Transcription in the untreated wt and mutants at $t=0$ min were set as 1 and values after $10 \mu \mathrm{M}$ treatment with IAA at $t=30$ min were calculated relative to these values and represent as one bar either in the wt diagram or in a mutant diagram $\left[{ }^{*} p<0.05,{ }^{* *} p<0.01\right.$, $* * * p<0.001 ;$ t-test].}

were up-regulated, not down-regulated (IAA19, SAUR25). Misexpressed reporter genes at $t=0 \mathrm{~min}$ were again dissimilar to those at $t=30 \mathrm{~min}$ (Supplementary Figure S4). No reporter gene was found to be mis-expressed in tir 1 at $t=0 \mathrm{~min}$, and 5-6 reporter genes in the receptor double mutants tirlafb 2 and tirlafb3.

\section{In Mutants Early Auxin-Induced Gene Expression Is Modulated Already at $10 \min$}

All genes represented by the mutants investigated here were not transcriptionally regulated by auxin for at least $1 \mathrm{~h}$ post treatment (Supplementary Figure S5, Nemhauser et al., 2006). After $4 \mathrm{~h}$ auxin treatment of Arabidopsis root tips the RNAs were analysed by second generation sequencing and the HTSeq software (Anders et al., 2015) and all genes defined by the mutants were found not to be regulated by in their transcription (unpublished data from Paulo Teixeira and Alan M. Jones, University of North Carolina). Nevertheless, regulation of transcription of test genes could be due to fast transcription and translation of another protein, which then could regulate TIR1/AFB activities. Therefore, we chose to select only five test genes with very rapid regulation of transcription out of our sample and quantify their auxin induction after $10 \mathrm{~min}$ (Figure 5). Ten minutes seems to be an extremely short time for expression of any protein that would have a function on TIR1/AFBs in the nucleus strongly enough to affect an auxin-induced readout. Therefore this time point seems suitable to exclude a transcriptional/translational back-coupling mechanism when starting with auxin binding to TIR1/AFBs.

At $t=10 \mathrm{~min}$, we measured expression of five genes (PIN3, IAA19, SAUR9, SAUR15, and SAUR23), chosen for their rapidity to respond to an auxin stimulus (Figure 5). In 20 out of 22 mutants at least one reporter gene was mis-regulated already after $10 \mathrm{~min}$ (Figure 5), and in most cases several were mis-regulated. In 14 mutants IAA19 and/or SAUR genes were transcriptionally increased compared to the wt at $10 \mathrm{~min}$ (lacs9, d6pk-1, tirlafb2, and tirlafb3). In $a b c b 1$ the induction of IAA19 expression by auxin was decreased and in $a b c b 19$ it was increased over the wt. Transcription of no reporter gene was significantly different from the wt at $10 \mathrm{~min}$ in the mutants ibr5 and tir 1 . Hence, already at $10 \mathrm{~min}$ in the great majority of all mutants at least one reporter and often 2-3 reporter genes were mis-regulated
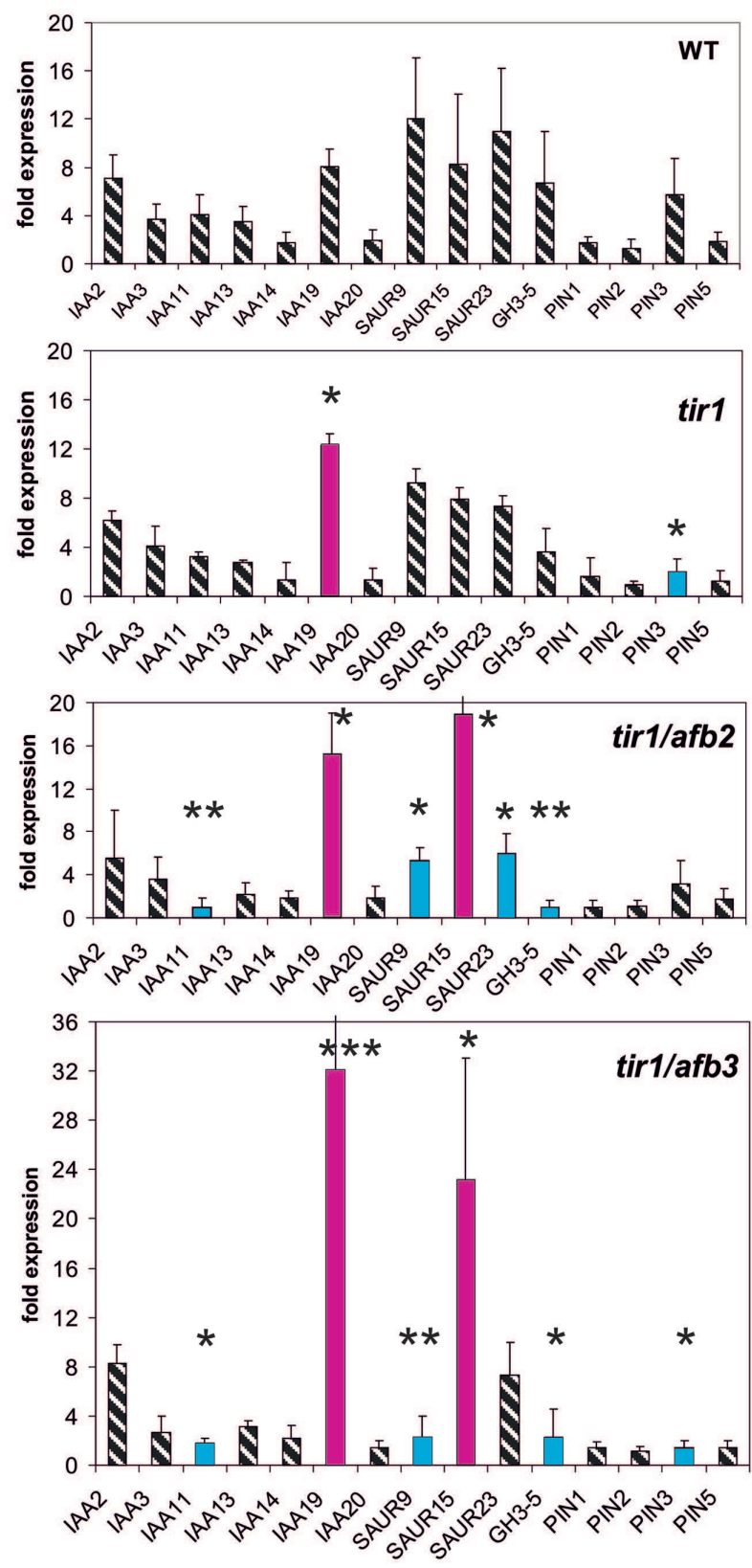

FIGURE 4 | Auxin-induced transcription of reporter genes in seedlings of the mutants tir1, tir1/afb2, tir1/afb3, and wt seedlings. Seedlings were grown in the light for 7 days and auxin treatment was 30 min. For each the wt and of the mutants one panel for the reporter genes is shown. Red bars indicate significant increased transcription and blue bars significantly decreased transcription of reporter genes in a comparison between the wt and mutant. Striped bars indicate no significant difference between the wt and the mutant. Transcription in the untreated wt and mutants at $t=0$ min were set as 1 and values after $10 \mu \mathrm{M}$ treatment by IAA at $t=30$ min were calculated relative to these values and represent as one bar either in the wt diagram or in a mutant diagram $\left[{ }^{*} p<0.05,{ }^{* *} p<0.01,{ }^{* * *} p<0.001\right.$; $t$-test]

at a significant level. As could be expected the extent of misregulation at $10 \mathrm{~min}$ was generally smaller than at $30 \mathrm{~min}$. Another aspect is that at $t=10 \mathrm{~min}$ over-shooting of the reporter 

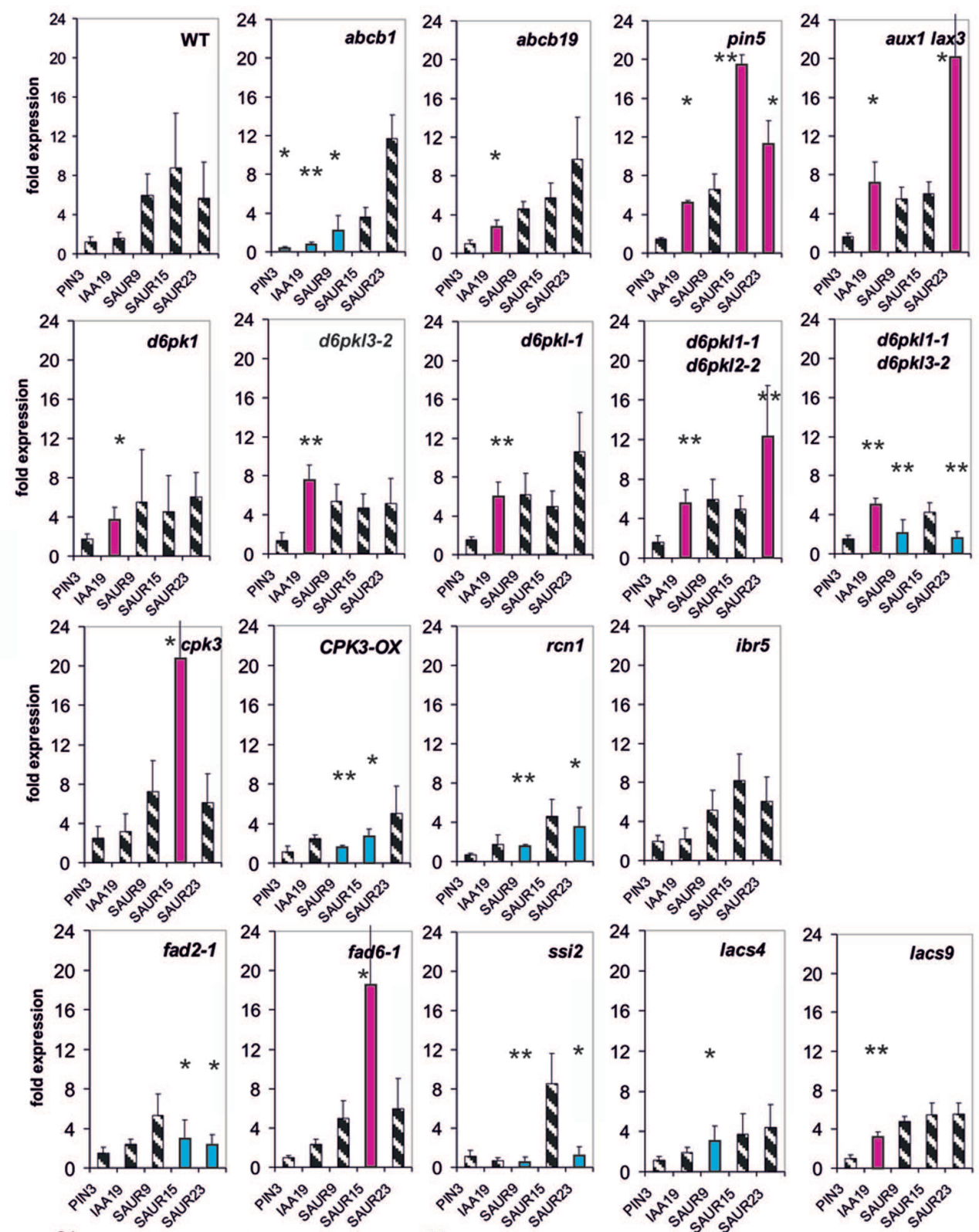

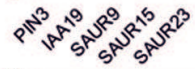
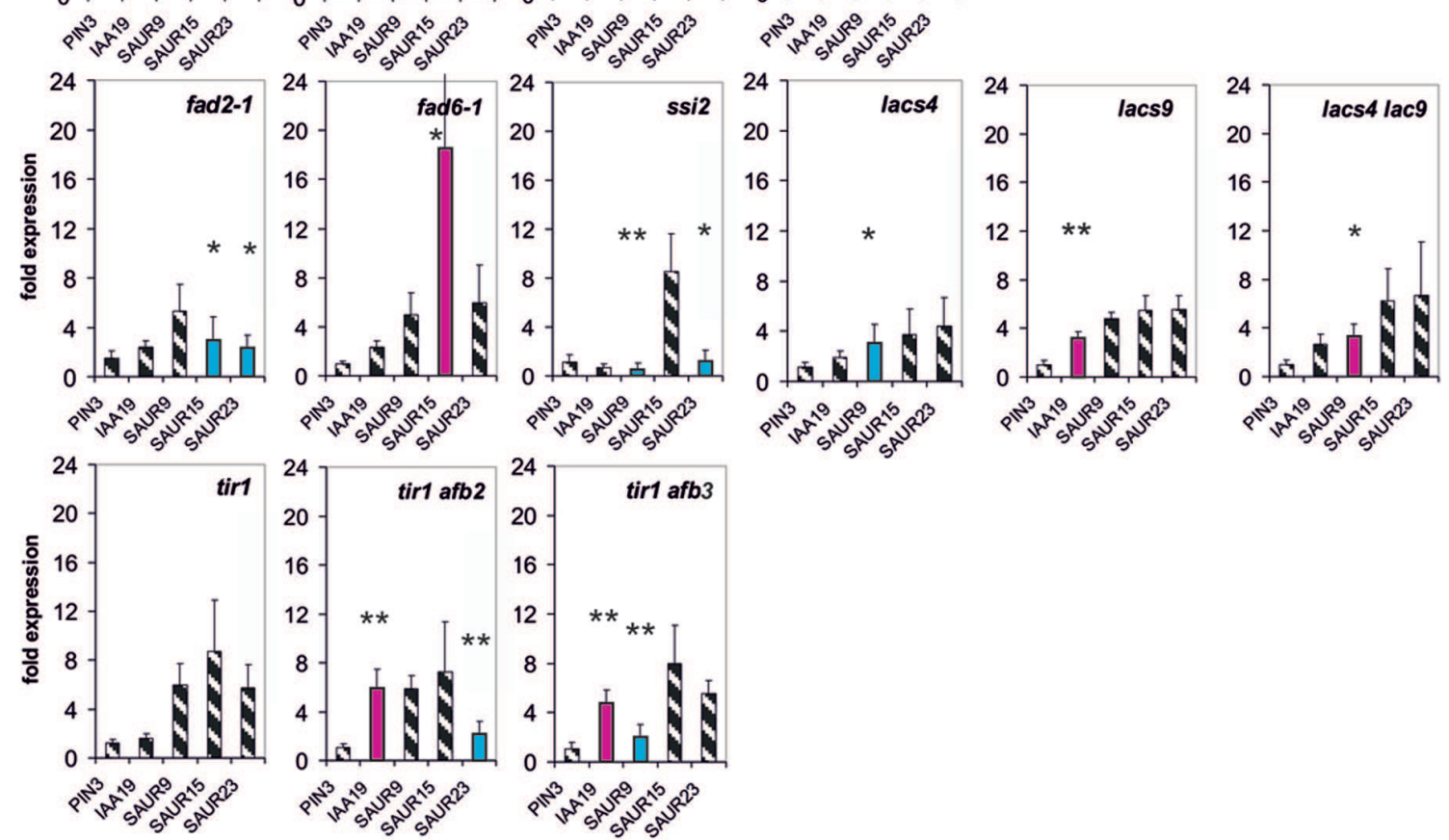

FIGURE 5 | Auxin-induced transcription of selected reporter genes in seedlings of all mutants used in this study and in wt seedlings. Seedlings were grown in the light for 7 days and auxin treatment was for 10 min. For each wt and of the mutants a panel for the reporter gene is shown. Red bars indicate significant increased transcription and blue bars significantly decreased transcription of reporter genes in a comparison between the wt and mutant. Striped bars indicate no significant difference between the wt and the mutant. Transcription in the untreated wt and mutants at $t=0$ min were set as 1 and values after $10 \mu \mathrm{M}$ treatment by IAA at $t=10$ min were calculated relative to these values and represent one bar either in the wt diagram or in a mutant diagram [ ${ }^{*} p<0.05,{ }^{* *} p<0.01, t$-test]. 
transcription (as compared to the wt) was found more often than at $t=30 \mathrm{~min}$.

However, with the exception of PIN3 after $t=30 \mathrm{~min}$, the expression of none of the mutant genes was up-regulated by auxin even for at least $1 \mathrm{~h}$ post auxin treatment (Supplementary Figure S5 and unpublished data from Paulo Teixeira and Alan M. Jones, University of North Carolina). This makes it clear that transcriptional regulation of the genes represented by the mutants was not the reason for the fast modulation of the TIR1/AFB-dependent readout. Expression of only some mutant genes was increased by auxin after $3 \mathrm{~h}$ (Supplementary Figure S5; IBR5, D6PK-1, and D6PK-2), which still excludes an effect of those mutant proteins/genes on TIR1-directed expression of reporter genes at $30 \mathrm{~min}$. We emphasize that our data are demonstrating for the 10-min auxin response, a receptor is necessary (Figure 5).

\section{Comparison of Long-Term Expression of Reporter Genes to their Short Term Induction by Auxin}

To allow a synopsis and a comparative analysis, we assembled all previously published results on ppla and abp1 mutants (Effendi et al., 2013, 2014, 2015; Labusch et al., 2013) and the experiments here into one simplifying scheme (Figure 6) of the mis-expression of the reporter genes after 10 (Figure 6A) and $30 \mathrm{~min}$ of $10 \mu \mathrm{M}$ auxin treatment (Figure $6 \mathrm{~B}$ ) and at $t=0 \mathrm{~min}$ (Figure 6C). The subcellular localization of the mutant gene products is summarized in Figure 6D. Previously unpublished data on ppla mutants at $t=0$ (Supplementary Figure S6) are incorporated into Figure 6C. The mutant lines are arranged vertically according to the number of mis-regulated reporter genes after $30 \mathrm{~min}$ of auxin application (Figure 6B), and the list of reporter genes is arranged with the most frequently misregulated reporter genes on the left side. In the scheme for $t=10 \mathrm{~min}$ (Figure 6A) and $t=0 \mathrm{~min}$ (Figure 6C) the genes were arranged accordingly. In the pplaI mutant, we had found eight mis-regulated reporter genes (Labusch et al., 2013; Effendi et al., 2014) and in the other ppla mutants four to seven at $t=30 \mathrm{~min}$ (Labusch et al., 2013; Effendi et al., 2014). All $a b p 1$ mutants had high scores of mis-regulated reporter genes at $t=30 \mathrm{~min}$ ( 8 in $a b p 1-5$ and $9-12$ in the engineered $a b p 1$ mutants at $t=30 \mathrm{~min})$. At $t=10$ the mutants $a b p 1-8$, abp19, $a b p 1-10$, and $a b p 1-11$ transcribed the reporter genes generally at a lower rate (Figure 6B; and data from Effendi et al., 2015). As stated before, the only weak mutants in our auxin-induced transcription test $(t=30 \mathrm{~min})$ were $t i r 1, \operatorname{lacs} 4, \operatorname{lacs} 8$, and $c p k 3$, probably because all of them are members of gene families so that genetic redundancy could play a role to reduce the impact of a single gene mutant.

Another aspect is that over-shooting of transcription of reporter genes in response to auxin is more frequent at $t=10 \mathrm{~min}$ (18 out of 34 responding reporter genes), than at $t=30 \mathrm{~min}$ (22 of 122 responding reporter genes). No over-shooting of reporter genes was found at $t=0 \mathrm{~min}$, which, however, is the consequence of 7 days development with a mutant genome. This indicates a time dependence, which, in view of the absence of a mechanistic model for TIR1 activity regulation, remains unexplained. It may rely again on the differing contributions of different members of the TIR1/AFB gene family due to genetic redundancy.

\section{DISCUSSION}

\section{Transcriptional Readout Controlled by the TIR1/AFB Receptors Is an Auxin Response}

Transcription of early auxin-induced genes is a valid auxin response. The reporter genes, we chose clearly displayed a regulatory pattern. Some genes such as PIN1, PIN2, and PIN5 are non-responsive, others like IAA19, SAUR9, SAUR15, and SAUR25 are highly and rapidly responsive (Figures 5 and $\mathbf{6 A , B}$ ) so that, as a whole, a clear pattern of fast responsiveness in the wt and in the mutants becomes apparent. This pattern of responsiveness is not identical to the pattern generated from transcription of the reporter genes at $t=0$, which corresponds to the changes in gene expression during 7 days seedling development (Figure 6C). It should be noted that already the mis-regulation of only one reporter gene in only one mutant would mean that, we would have to conclude that an auxin receptor-driven process depending on this mutant gene product causes this. In fact, we found several mis-regulated genes in many mutants. Hence, deviations in single values do not undermine this hypothesis, the complete pattern is the true argument for it. The measurements at $t=30 \mathrm{~min}$ argue for a receptor-driven pathway to regulate TIR1/AFB activities with special emphasis for all mutant gene products which are membrane proteins (Figure 6D). This is given by the fact that membrane protein amounts are not rapidly changed by transcription/translation. Their expression at the plasma membrane needs $1 \mathrm{~h}$ or longer (Scherer, 2011). Changes in transcription of $A B P 1$, PIN2, PIN3, $A B C B 1, A B C B 19$, and $A U X 1 / L A X 3$ cannot affect expression at the plasma membrane within 30 min to cause back-coupling to TIR1. Similarly, it seems very unlikely that changes in membrane lipid composition will be measurable after $30 \mathrm{~min}$ transcription of genes of reporter genes in LACS4, LACS9, SSI2, FAD2-1, or FAD6-1 mutants. Lipid compositions are the target of these genes so that their changes could result in activity changes of membrane proteins, e.g., transport proteins which are influenced by lipid composition so that timing, either $10 \mathrm{~min}$ or $30 \mathrm{~min}$ auxin treatment, is not the point (Roudier et al., 2010; Markham et al., 2011).

Almost all mutants employed in this and our previous studies concern genes known to have functions in auxin signaling (see references in Supplementary Table S1). Only few have not yet been investigated in detail as potential auxin signaling mutants like $c p k 3, C P K 3-O X$, and some pplas but actually only $c p k 3$ was truly similar to the wt in its transcriptional responsiveness at the 10 and 30 min (Figures 2 and 5). Another such example is tirl, which is also very similar to the wt in our results, probably because of the genetic redundancy of this receptor family (Figure 4). 
A
$10 \min$

B

$30 \min$

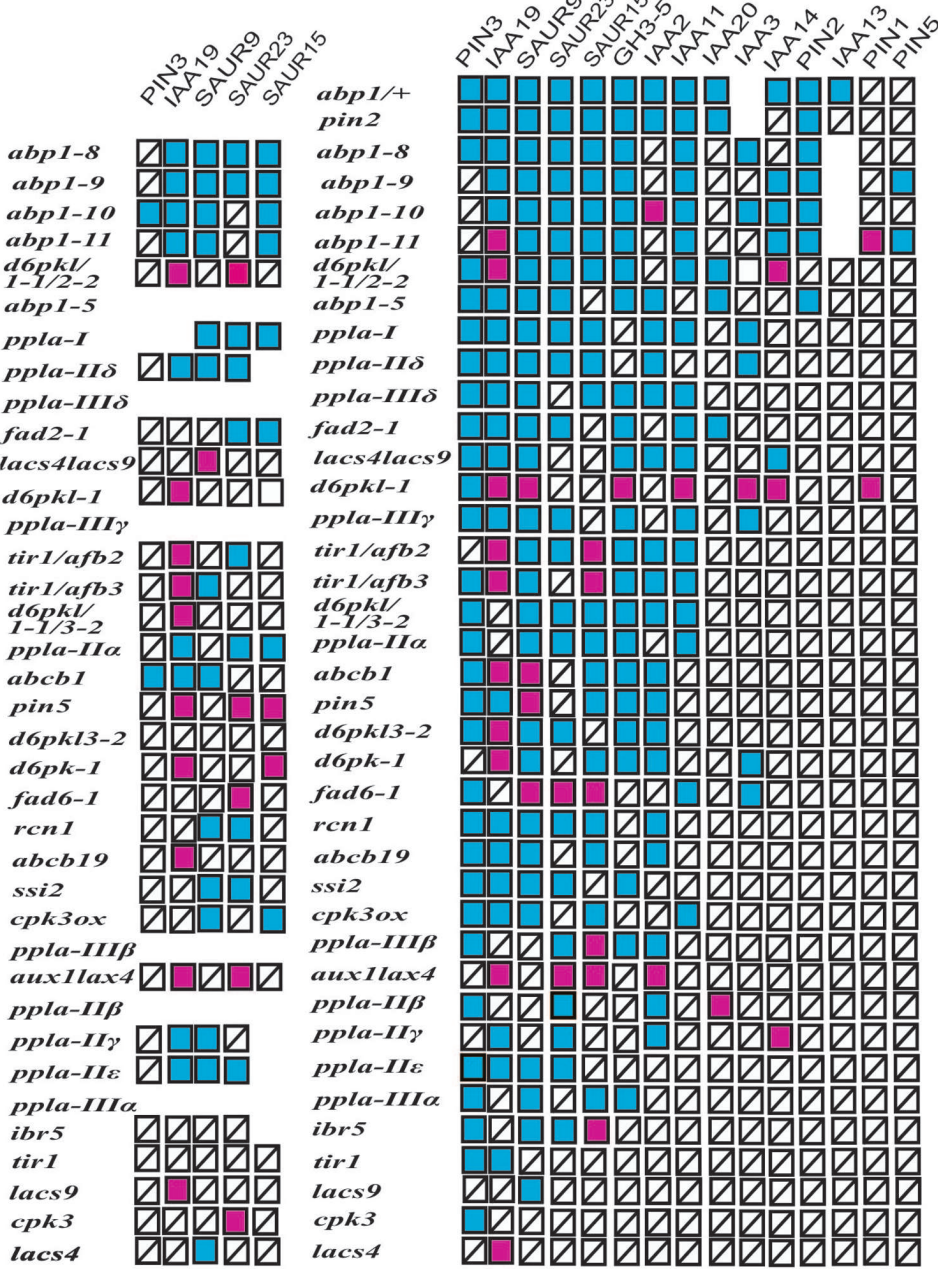

C

$0 \min$

C

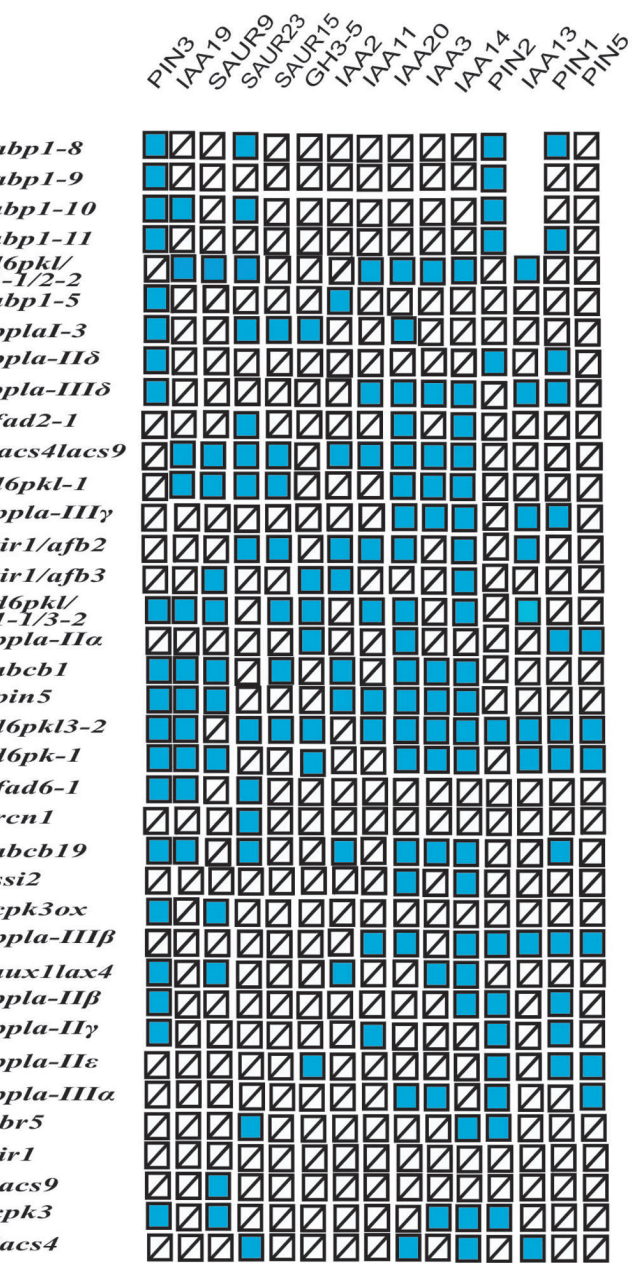

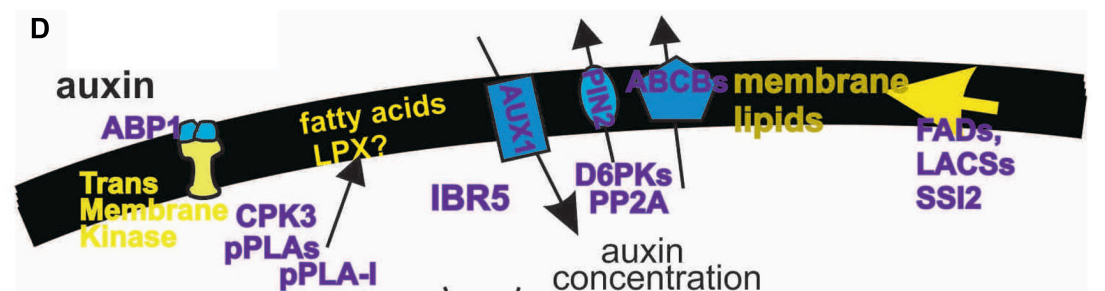

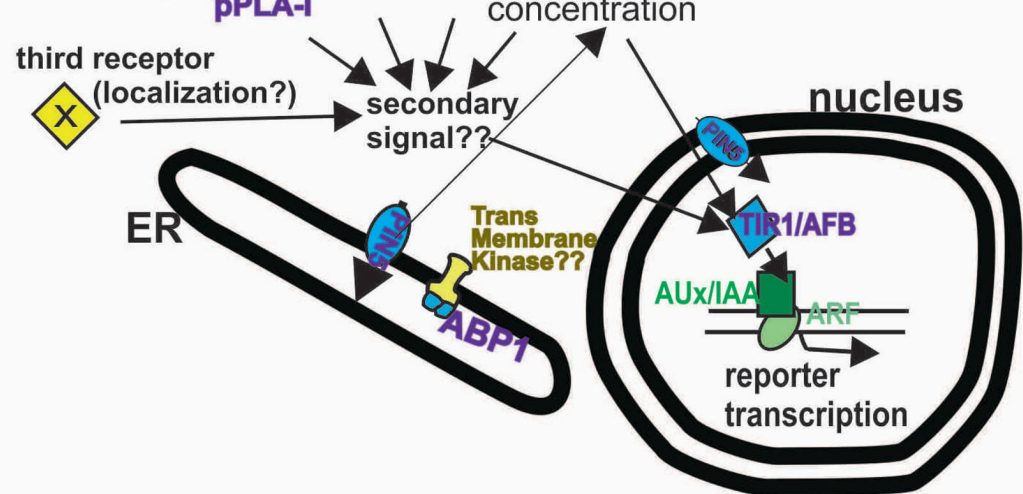

FIGURE 6 | Continued 


\section{FIGURE 6 | Continued}

(A-C) Summary of auxin-induced transcription in mutants and the number of defects in early auxin-induced gene expression. Red squares represent increased transcription as compared to the wt and blue squares represent decreased values than those found in the wt. Squares with a black bar represent transcription not significantly different from the wt. Previously published data are incorporated into the figure (Effendi and Scherer, 2011; Effendi et al., 2011, 2013, 2014; Labusch et al., 2013). To allow for a synopsis and a comparative analysis, we assembled all previously published results on ppla and abp 1 mutants (Effendi et al., 2013,2014 2015; Labusch et al., 2013) and the experiments here into one scheme. The mis-expression of the reporter genes in plants after 10 min of auxin treatment (Figure 6A), after 30 min of $10 \mu \mathrm{M}$ auxin treatment (Figure 6B), and at $t=0$ min are presented (Figure 6C). Data on ppla mutants at $t=0$ (Supplementary Figure S6) are included into Figure $\mathbf{6 C}$. Mutants were sorted vertically by the number of mis-regulated reporter genes. Reporter genes were sorted vertically according to the number of deviations from the wt. Values that were not quantified are left as empty spaces. In the schemes for $t=0$ min and $t=10$ min, this arrangement is done accordingly. Only tir1, lacs4, lacs8, and cpk3 were weak mutants in this auxin-induced transcription test. (D) The mutant gene products are arranged into a schematic cell to indicate their subcellular localization. A hypothetical linkage between TIR1 and ABP1 is indicated by arrows. Also, the possibility of a hypothetical third receptor with unknown localization is indicated.

Transcription of all of the genes defined by the mutants is not modulated by auxin for at least $1 \mathrm{~h}$ with the interesting exception of ABP1 (Effendi et al., 2015). To increase of the amount of ABP1 in the plasma membrane, however, takes considerably longer than the first effects on transcription of $A B P 1$ because the time for transport to the plasma membrane is at least $1 \mathrm{~h}$ (Scherer, 2011). Therefore, transcriptional feedback or feedforward through these mutant genes is not possible in less than an hour. Transcription/translation, however, is the only mechanism for signal propagation available to the TIR1/AFB receptors (Mockaitis and Estelle, 2008). We found aberrant transcription of 2-3 reporter genes already in 11 mutant lines after $10 \mathrm{~min}$ and of one reporter genes in nine mutant lines out of 22 total (Figure 5). Therefore, we must conclude that the output of TIR1/AFBs is modulated within $10 \mathrm{~min}$ by an auxin-initiated, receptor-driven process.

Can TIR1/AFBs be regulated within $10 \mathrm{~min}$ ? In our previous report measuring the degradation of an Aux/IAA1-luciferase hybrid protein, we showed with this method modulation of TIR1 activity after $4 \mathrm{~min}$ by inhibitors of pPLA (Scherer et al., 2007). Yu et al. (2015) showed that enhancing the untethering of TIR1 from the SCF complex inhibits TIR1 activity so that this reaction could provide a model idea to regulate TIR1 enzymatic activity. In a speculative review, neddylation of the SCF/TIR1 complex was hypothesized to be a mechanism of regulation of TIR1 so that potential regulation of TIR1 receptors cannot be excluded (Parry and Estelle, 2004).

The identity of the transcriptional/translational mechanism, starting with TIR1/AFB auxin perception, that can so rapidly regulate TIR1 activity remains unknown. It would require an auxin-induced, rapid biosynthesis of a protein (i.e., a translational mechanism) that is capable of changing TIR1/AFB activities. But such a protein has yet to be found.

Logically, the auxin-induced transcriptional response of reporter genes requires a receptor to initiate such fast downstream responses (Scherer et al., 2012) even if regulation would affect solely mRNA levels. This could be an as yet unknown auxin receptor or even ABP1. ABP1 binds to four transmembrane kinases, which can activate RIC/ROP signaling (Dai et al., 2013; Xu et al., 2014) and could employ a posttranslational mechanism, which can operate on the time scale of minutes. Conceivably, a receptor kinase could phosphorylate various proteins or initiate phosphorylation cascades so that signal transmission within minutes into the cytosol would be a possibility. It should also be kept in mind that numerous auxin responses are known, which have been detected in fewer than $10 \mathrm{~min}$ (Scherer, 2011) and which are difficult to reconcile with statements that $\mathrm{ABP} 1$ has no function in auxin signaling (Gao et al., 2015). This can be said despite the recent revelation that defects in the neighboring BSM gene cause the embryo-lethal phenotype in abp1-1 (Dai et al., 2015; Michalko et al., 2015). Other rapid responses to auxin are still linked to a functional ABP1 (Robert et al., 2010; Xu et al., 2010, 2014; Dai et al., 2013). This statement is valid in spite of the equally surprising failure of the ethanol-inducible repression of ABP1 function by an antibody fragment (Michalko et al., 2016). We conclude that, we can neither completely disprove TIR1/AFBs to be the receptors for the observed changes in auxin-induced responsiveness of transcription nor can we completely prove that $\mathrm{ABP} 1$ is the receptor for that response. The possibility that a third receptor has this function, however, seems remote.

\section{AUTHOR CONTRIBUTIONS}

CL designed research and experiments. YE designed research and experiments. MF provided material and wrote article. GS designed Research and wrote article.

\section{FUNDING}

Support from the Deutsches Zentrum für Luft- und Raumfahrt (contract number 50WB1333) and from the Deutsche Forschungsgemeinschaft (Sche207/24-1) is gratefully acknowledged. The publication of this article was funded by the Open Access Fund of the Leibniz Universität Hannover.

\section{ACKNOWLEDGMENTS}

Arabidopsis thaliana mutant lines fad2-1, fad6, and ssi2 were provided by P. Kachroo, lacs4, lacs9, and lacs4 lacs 9 by M. Fulda. The ibr 5 was from B. Bartel, $r c n 1$ from A. Delong, the $d 6 p k$ lines were provided by M. Zourelidou. The $c p k 3-2$ line was given to us by $\mathrm{M}$. Teige and the $C P K 3-O X$ over-expresser by $\mathrm{S}$. Rietz. The $a b c b 1-1, a b c b 19-1$, and pin5-5 lines were given to us by M. Geisler, 
aux1-21/lax3 by R. Swarup. The mutants tir1-10 and double mutants tir1-10/afb2-3, and tir1-10/afb3-4 and were kindly given to us by M. Quint. We thank Dr. T. Buckhout for editing the English language.

\section{REFERENCES}

Abel, S., and Theologis, A. (1996). Early genes and auxin action. Plant Physiol. 111, 9-17. doi: 10.1104/pp.111.1.9

Anders, S., Pyl, P. T., and Huber, W. (2015). HTSeq-a Python framework to work with high-throughput sequencing data. Bioinformatics 31, 166-169. doi: 10.1093/bioinformatics/btu638

Badescu, G. O., and Napier, R. M. (2006). Receptors for auxin: will it all end in TIRs? Trends Plant Sci. 11, 217-223. doi: 10.1016/j.tplants.2006. 03.001

Calderon-Villalobos, L. I., Lee, S., De Oliveira, C., Ivetac, A., Brandt, W., Armitage, L., et al. (2012). A combinatorial TIR1/AFB-Aux/IAA co-receptor system for differential sensing of auxin. Nat. Chem. Biol. 8, 477-485. doi: 10.1038/nchembio.926

Chae, K., Isaacs, C. G., Reeves, P. H., Maloney, G. S., Muday, G. K., Nagpal, P., et al. (2012). Arabidopsis SMALL AUXIN UP RNA63 promotes hypocotyl and stamen filament elongation. Plant J. 71, 684-697. doi: 10.1111/j.1365313X.2012.05024.X

Chen, J. G., Ullah, H., Young, J. C., Sussman, M. R., and Jones, A. M. (2001). ABP1 is required for organized cell elongation and division in Arabidopsis embryogenesis. Genes Dev. 15, 902-911. doi: 10.1101/gad. 866201

Dai, N., Wang, W., Patterson, S. E., and Bleecker, A. B. (2013). The TMK subfamily of receptor-like kinases in Arabidopsis display an essential role in growth and a reduced sensitivity to auxin. PLoS ONE 8:e60990. doi: 10.1371/journal.pone.0060990

Dai, X., Zhang, Y., Zhang, D., Chen, J., Gao, X., Estelle, M., et al. (2015). Embryonic lethality of Arabidopsis abp1-1 is caused by deletion of the adjacent BSM gene. Nat. Plants 1, 15183. doi: 10.1038/nplants.2015.183

Effendi, Y., Ferro, N., Labusch, C., Geisler, M., and Scherer, G. F. E. (2015). Complementation of an embryo-lethal abp1 T-DNA insertion mutant with mutated AUXIN-BINDING-PROTEIN 1 (ABP1) cDNAs reveals crosstalk of ABP1 and phytochrome. J. Exp. Bot. 66, 403-418. doi: 10.1093/jxb/eru433

Effendi, Y., Jones, A. M., and Scherer, G. F. E. (2013). AUXIN-BINDINGPROTEIN1 (ABP1) in phytochrome-B-controlled responses. J. Exp. Bot. 64, 5065-5074. doi: 10.1093/jxb/ert294

Effendi, Y., Radatz, K., Rietz, S., Labusch, C., Wimalasekera, R., Zeidler, M., et al. (2014). Mutants of phospholipase A (pPLA-I) have a red light and auxin phenotype. Plant Cell Environ. 37, 1626-1640. doi: 10.1111/pce.12278

Effendi, Y., Rietz, S., Fischer, U., and Scherer, G. F. E. (2011). The heterozygous abp1/ABP1 insertional mutant has defects in functions requiring polar auxin transport and in regulation of early auxin-regulated genes. Plant J. 65, 282-294. doi: 10.1111/j.1365-313X.2010.04420.x

Effendi, Y., and Scherer, G. F. E. (2011). Auxin binding-protein1 (ABP1), a receptor to regulate auxin transport and early auxin genes in an interlocking system with PIN proteins and the receptor TIR1. Plant Signal. Behav. 6, 1101-1103. doi: 10.4161/psb.6.8.16403

Fuglsang, A. T., Kristensen, A., Cuin, T. A., Schulze, W. X., Persson, J., Thuesen, K. H., et al. (2014). Receptor kinase-mediated control of primary active proton pumping at the plasma membrane. Plant J. 80, 951-964. doi: 10.1111/tpj.12680

Gao, Y., Zhang, Y., Zhang, D., Dai, X., Estelle, M., and Zhao, Y. (2015). Auxin binding protein $1(\mathrm{ABP} 1)$ is not required for either auxin signaling or Arabidopsis development. Proc. Natl. Acad. Sci. U.S.A. 112, 2275-2280. doi: $10.1073 /$ pnas. 1500365112

Garbers, C., DeLong, A., Deruére, J., Bernasconi, P., and Söll, D. (1996). A mutation in protein phosphatase $2 \mathrm{~A}$ regulatory subunit A affects auxin transport in Arabidopsis. EMBO J. 15, 2115-2124.

Geisler, M., Blakeslee, J. J., Bouchard, R., Lee, O. R., Vincenzetti, V., Bandyopadhyay, A., et al. (2005). Cellular efflux of auxin catalyzed by the Arabidopsis MDR/PGP transporter AtPGP1. Plant J. 44, 179-194. doi: 10.1111/j.1365-313X.2005.02519.x

\section{SUPPLEMENTARY MATERIAL}

The Supplementary Material for this article can be found online at: http://journal.frontiersin.org/article/10.3389/fpls.2016.00995

Geisler, M., Kolukisaoglu, H. U., Bouchard, R., Billion, K., Berger, J., Saal, B., et al. (2003). TWISTED DWARF1, a unique plasma membrane-anchored immunophilin-like protein, interacts with Arabidopsis multidrug resistancelike transporters AtPGP1 and At-PGP19. Mol. Biol. Cell. 14, 4238-4249. doi: 10.1091/mbc.E02-10-0698

Jurado, S., Abraham, Z., Manzano, C., López-Torrejón, G., Pacios, L. F., and del Pozo, J. C. (2010). HThe Arabidopsis cell cycle F-box protein SKP2A binds to auxin. Plant Cell 22, 3891-3904.

Kachroo, A., Lapchyk, L., Fukushige, H., Hildebrand, D., Klessig, D., and Kachroo, P. (2003). Plastidial fatty acid signaling modulates salicylic acid- and jasmonic acid-mediated defense pathways in the Arabidopsis ssi2 mutant. Plant Cell 15, 2952-2965. doi: 10.1105/tpc. 017301

Labusch, C., Shishova, M., Effendi, Y., Li, M., Wang, X., and Scherer, G. F. E. (2013). Patterns and timing in expression of early auxin-induced genes in phospholipase A (pPLA) T-DNA insertion mutants reveal a function in auxin signaling. Mol. Plant 6, 1473-1486. doi: 10.1093/mp/sst053

Markham, J. E., Molino, D., Gissot, L., Bellec, Y., Hématy, K., Marion, J., et al. (2011). Sphingolipids containing very-long-chain Fatty acids define a secretory pathway for specific polar plasma membrane protein targeting in Arabidopsis. Plant Cell 23, 2362-2378. doi: 10.1105/tpc.110.080473

Mehlmer, N., Wurzinger, B., Stael, S., Hofmann-Rodrigues, D., Csaszar, E., Pfister, B., et al. (2010). The Ca2+-dependent protein kinase CPK3 is required for MAPK-independent salt-stress acclimation in Arabidopsis. Plant J. 63, 484-498. doi: 10.1111/j.1365-313X.2010.04257.x

Michalko, J., Draveckám, M., Bollenbach, T., and Friml, J. (2015). Embryo-lethal phenotypes in early abpl mutants are due to disruption of the neighboring BSM gene. F1000Res. 4:1104. doi: 10.12688/f1000research.7143.1

Michalko, J., Glanc, M., Perrot-Rechenmann, C., and Friml, J. (2016). Strong morphological defects in conditional Arabidopsis abp1 knock-down mutants generated in absence of functional ABP1 protein. F1000Res. 5:86. doi: 10.12688/f1000research.7654.1

Mockaitis, K., and Estelle, M. (2008). Auxin receptors and plant development: a new signaling paradigm. Annu. Rev. Cell Dev. Biol. 24, 55-80. doi: 10.1146/annurev.cellbio.23.090506.123214

Mockaitis, K., and Howell, S. H. (2000). Auxin induces mitogenic activated protein kinase (MAPK) activation in roots of Arabidopsis seedlings. Plant J. 24, 785-796. doi: 10.1111/j.1365-313X.2000.00921.x

Monroe-Augustus, M., Zolman, B. K., and Bartel, B. (2003). IBR5, a dual-specificity phosphatase-like protein modulating auxin and abscisic acid responsiveness in Arbidopsis. Plant Cell 15, 2979-2991. doi: 10.1105/tpc.017046

Mravec, J., Skůpa, P., Bailly, A., Hoyerová, K., Krecek, P., Bielach, A., et al. (2009). Subcellular homeostasis of phytohormone auxin is mediated by the ERlocalized PIN5 transporter. Nature 459, 1136-1140. doi: 10.1038/nature08066

Napier, R. M., David, K. M., and Perrot-Rechenmann, C. (2002). A short history of auxin-binding proteins. Plant Mol. Biol. 49, 339-348. doi: 10.1023/A:1015259130955

Nemhauser, J. L., Hong, F., and Chory, J. (2006). Different plant hormones regulate similar processes through largely nonoverlapping transcriptional responses. Cell 126, 467-475. doi: 10.1016/j.cell.2006.05.050

Paponov, I. A., Paponov, M., Teale, W., Menges, M., Chakrabortee, S., Murray, J. A. H., et al. (2008). Comprehensive transcriptome analysis of auxin responses in Arabidopsis. Mol. Plant 1, 321-337. doi: 10.1093/mp/ssm021

Parry, G., Calderon-Villalobos, L. I., Prigge, M., Peret, B., Dharmasiri, S., Itoh, H., et al. (2009). Complex regulation of the TIR1/AFB family of auxin receptors. Proc. Natl. Acad. Sci. U.S.A. 106, 22540-22545. doi: 10.1073/pnas.0911967106

Parry, G., and Estelle, M. (2004). Regulation of cullin-based ubiquitin ligases by the Nedd8/RUB ubiquitin-like proteins. Semin. Cell Dev. Biol. 15, 221-229. doi: 10.1016/j.semcdb.2003.12.003

Paul, R., Holk, A., and Scherer, G. F. E. (1998). Fatty acids and lysophospholipids as potential second messengers in auxin action. Rapid activation of phospholipase 
A2 activity by auxin in suspension-cultured parsley and soybean cells. Plant J. $16,601-611$.

Péret, B., Swarup, K., Ferguson, A., Seth, M., Yang, Y., Dhondt, S., et al. (2012). AUX/LAX genes encode a family of auxin influx transporters that perform distinct functions during Arabidopsis development. Plant Cell 24, 2874-2885. doi: $10.1105 /$ tpc.112.097766

Petrasek, J., Mravec, J., Bouchard, R., Blakeslee, J. J., Abas, M., Seifertova, D., et al. (2006). PIN proteins perform a rate-limiting function in cellular auxin efflux. Science 312, 914-918. doi: 10.1126/science.1123542

Pfaffl, M. W., Horgan, G. W., and Dempfle, L. (2002). Relative expression software tool $\left(\mathrm{REST}^{\odot}\right)$ for group-wise comparison and statistical analysis of relative expression results in real-time PCR. Nucleic Acids Res. 30:e36. doi: 10.1093/nar/30.9.e36

Rietz, S., Dermendjiev, G., Oppermann, E., Tafesse, F. G., Effendi, Y., Holk, A., et al. (2010). Roles of Arabidopsis patatin-related phospholipases A in root development are related to auxin responses and phosphate deficiency. Mol. Plant 3, 534-538. doi: 10.1093/mp/ssp109

Robert, S., Kleine-Vehn, J., Barbez, E., Sauer, M., Paciorek, T., Baster, P., et al. (2010). ABP1 mediates auxin inhibition of clathrin-dependent endocytosis in Arabidopsis. Cell 143, 111-121. doi: 10.1016/j.cell.2010.09.027

Roudier, F., Gissot, L., Beaudoin, F., Haslam, R., Michaelson, L., Marion, J., et al. (2010). Very-long-chain fatty acids are involved in polar auxin transport and developmental patterning in Arabidopsis. Plant Cell 22, 364-375. doi: 10.1105/tpc.109.071209

Salehin, M., Bagchi, R., and Estelle, M. (2015). SCFTIR1/AFB-based auxin perception: mechanism and role in plant growth and development. Plant Cell 27, 9-19. doi: 10.1105/tpc.114.133744

Scherer, G. F. E. (2011). AUXIN-BINDING-PROTEIN1, the second auxin receptor: what is the significance of a two-receptor concept in plant signal transduction? J. Exp. Bot. 62, 3339-3357. doi: 10.1093/jxb/err033

Scherer, G. F. E., Labusch, C., and Effendi, Y. (2012). Phospholipases and the network of auxin signal transduction with ABP1 and TIR1 as two receptors: a comprehensive and provocative model. Front. Plant Sci. 3:56. doi: $10.3389 /$ fpls.2012.00056

Scherer, G. F. E., Zahn, M., Callis, J., and Jones, A. M. (2007). A role for phospholipase A in auxin-regulated gene expression. FEBS Lett. 581, 42054211. doi: 10.1016/j.febslet.2007.07.059

Spartz, A. K., Lee, S. H., Wenger, J. P., Gonzalez, N., Itoh, H., Inzé, D., et al. (2012). The SAUR19 subfamily of SMALL AUXIN UP RNA genes promote cell expansion. Plant J. 70, 978-990. doi: 10.1111/j.1365-313X.2012.04946.x

Spartz, A. K., Ren, H., Park, M. Y., Grandt, K. N., Lee, S. H., Murphy, A. S., et al. (2014). SAUR Inhibition of PP2C-D phosphatases activates plasma membrane H+-ATPases to promote cell expansion in Arabidopsis. Plant Cell 26, 21292142. doi: $10.1105 /$ tpc. 114.126037

Staswick, P. E., Serban, B., Rowe, M., Tiryaki, I., Maldonado, M. T., Maldonado, M. C., et al. (2005). Characterization of an Arabidopsis enzyme family that conjugates amino acids to indole-3-acetic acid. Plant Cell 17, 616-627. doi: $10.1105 /$ tpc. 104.026690

Strader, L. C., Monroe-Augustus, M., and Bartel, B. (2008). The IBR5 phosphatase promotes Arabidopsis auxin responses through a novel mechanism distinct from TIR1-mediated repressor degradation. BMC Plant Biol. 8:41. doi: 10.1186/1471-2229-8-41

Takahashi, K., Hayashi, K., and Kinoshita, T. (2012). Auxin activates the plasma membrane $\mathrm{H}+$-ATPase by phosphorylation during hypocotyl elongation in Arabidopsis. Plant Physiol. 159, 632-641. doi: 10.1104/pp.112.196428
Tan, X., Calderon-Villalobos, L. I., Sharon, M., Zheng, C., Robinson, C. V., Estelle, M., et al. (2007). Mechanism of auxin perception by the TIR1 ubiquitin ligase. Nature 446, 640-645. doi: 10.1038/nature05731

Titapiwatanakun, B., Blakeslee, J. J., Bandyopadhyay, A., Yang, H., Mravec, J., Sauer, M., et al. (2009). ABCB19/PGP19 stabilises PIN1 in membrane microdomains in Arabidopsis. Plant J. 57, 27-44. doi: 10.1111/j.1365313X.2008.03668.x

Vieten, A., Vanneste, S., Wisniewska, J., Benková, E., Benjamins, R., Beeckman, T., et al. (2005). Functional redundancy of PIN proteins is accompanied by auxindependent cross-regulation of PIN expression. Development 132, 4521-4531. doi: $10.1242 / \mathrm{dev} .02027$

Wallis, J. G., and Browse, J. (2002). Mutants of Arabidopsis reveal many roles for membrane lipids. Prog. Lipid Res. 41, 254-278. doi: 10.1016/S01637827(01)00027-3

Xu, T., Dai, N., Chen, J., Nagawa, S., Cao, M., Li, H., et al. (2014). Cell surface ABP1-TMK auxin-sensing complex activates ROP GTPase signaling. Science 343, 1025-1028. doi: 10.1126/science. 1245125

Xu, T., Wen, M., Nagawa, S., Fu, Y., Chen, J. G., Wu, M. J., et al. (2010). Cell surface- and Rho GTPase-based auxin signaling controls cellular interdigitation in Arabidopsis. Cell 143, 99-110. doi: 10.1016/j.cell.2010.09.003

Yu, H., Zhang, Y., Moss, B. L., Bargmann, B. O., Wang, R., Prigge, M., et al. (2015). Untethering the TIR1 auxin receptor from the SCF complex increases its stability and inhibits auxin response. Nat. Plants 1, 14030. doi: 10.1038/nplants.2014.30

Zegzouti, H., Li, W., Lorenz, T. C., Xie, M., Payne, C. T., Smith, K., et al. (2006). Structural and functional insights into the regulation of Arabidopsis AGC VIIIa kinases. J. Biol. Chem. 281, 35520-35530. doi: 10.1074/jbc.M605167200

Zenser, N., Dreher, K. A., Edwards, S. R., and Callis, J. (2003). Acceleration of Aux/IAA proteolysis is specific for auxin and independent of AXR1. Plant J. 35, 285-294. doi: 10.1046/j.1365-313X.2003.01801.x

Zhang, J., Liu, H., Sun, J., Li, B., Zhu, Q., Chen, S., et al. (2012). Arabidopsis fatty acid desaturase FAD2 is required for salt tolerance during seed germination and early seedling growth. PLoS ONE 7:e30355. doi: 10.1371/journal.pone.0030355

Zhang, J. T., Zhu, J. Q., Zhu, Q., Liu, H., Gao, X. S., and Zhang, H. X. (2009). Fatty acid desaturase-6 (Fad6) is required for salt tolerance in Arabidopsis thaliana. Biochem. Biophys. Res. Commun. 390, 469-474. doi: 10.1016/j.bbrc.2009.09.095

Zourelidou, M., Absmanner, B., Weller, B., Barbosa, I. C., Willige, B. C., Fastner, A., et al. (2014). Auxin efflux by PIN-FORMED proteins is activated by two different protein kinases. D6 PROTEIN KINASE and PINOID. Elife 3:e02860. doi: 10.7554/eLife.02860

Zourelidou, M., Müller, I., Willige, B. C., Nill, C., Jikumaru, Y., Li, H., et al. (2009). The polarly localized D6 PROTEIN KINASE is required for efficient auxin transport in Arabidopsis thaliana. Development 136, 627-636. doi: $10.1242 /$ dev. 028365

Conflict of Interest Statement: The authors declare that the research was conducted in the absence of any commercial or financial relationships that could be construed as a potential conflict of interest.

Copyright (c) 2016 Labusch, Effendi, Fulda and Scherer. This is an open-access article distributed under the terms of the Creative Commons Attribution License (CC BY). The use, distribution or reproduction in other forums is permitted, provided the original author(s) or licensor are credited and that the original publication in this journal is cited, in accordance with accepted academic practice. No use, distribution or reproduction is permitted which does not comply with these terms. 